\title{
¿"Imperio inca" o Tahuantinsuyo? La singularidad histórica andina en los currículos y textos escolares ecuatorianos
}

\author{
( Javier González Díez" \\ Juan Carlos Brito Román"*
}

Fecha de recepción: 12 de julio de 2019. Fecha de aceptación: 24 de abril de 2020

Palabras clave

Tahuantinsuyo historia escolar

Ecuador eurocentrismo

\section{Resumen}

El propósito de este artículo es explorar las relaciones entre la etnohistoria y la historia escolar en el ámbito de la construcción de las narraciones del pasado que caracterizan las memorias históricas oficiales. A través del análisis de currículos y textos escolares de historia en Ecuador examinamos la manera en la que se define e interpreta la historia incaica, de modo particular en lo relativo la forma política del Tahuantinsuyo. En el análisis evidenciamos que la singularidad histórica de la experiencia política andina es tratada por los textos con categorías eurocéntricas. De esta manera, concluimos que los aportes de la investigación etnohistórica -en términos de nuevas visiones e interpretaciones sobre el pasado americano- no han sido recibidos por la historia escolar ecuatoriana y reflexionamos sobre cuál es el significado de la historia que se enseña hoy a los estudiantes.

\section{"Inca Empire" or Tahuantinsuyo? Andean historical singularity in Ecuadorian curriculums and school textbooks}

Key words

Tahuantinsuyo school history

Ecuador Eurocentrism

\section{Abstract}

The main purpose of this article is to explain the correlations between school history and ethnohistory related to narratives about the past which characterize the official historic memories. Through the analysis of Ecuadorian school

\footnotetext{
* Universidad Nacional de Educación (UNAE), Grupo de Investigación en Educación Decolonial y Epistemologías del Sur (EduSUR). Azogues, Ecuador. E-mail: javier.gonzalez@unae.edu.ec

** Universidad Nacional de Educación (UNAE), Grupo de Investigación en Educación Decolonial y Epistemologías del Sur (EduSUR). Azogues, Ecuador. E-mail: juan.brito@unae.edu.ec
} 
curriculums and texts of history it is examined how the Inca history is defined and interpreted, particularly related to the politic form of the Tahuantinsuyo. The analysis showed that the historic singularity of the Andean political experience is exposed by the school texts with eurocentric categories. Thus, our conclusion is that the contributions of the ethnohistorical research -in terms of new visions and interpretations about the American past- have not being received by the Ecuadorian history school books and we pose a reflection regarding the meaning of the history taught to students today

\title{
Introducción: La historia escolar latinoamericana entre herencias eurocéntricas y alternativas desde la etnohistoria
}

\author{
El deseo indígena hacia la unidad se expresa a través de la voz Tahuantisuyu, \\ que significa las "cuatro regiones unidas entre sí", y que manifiesta un intento o \\ impulso hacia la integración, posiblemente inconsciente, que desgraciadamente \\ nunca se logró y se vio truncada por la aparición de las huestes de Pizarro. \\ Faltó tiempo a los cusqueños para consolidar sus propósitos. \\ Por estos motivos nos inclinamos a emplear la palabra Tahuantinsuyu en \\ lugar de "Imperio", pues el significado cultural de esta última no interpreta, \\ ni corresponde a la realidad andina, sino a situaciones relativas a otros \\ continentes (Rostworowski, 1988: 15-16).
}

Este artículo usa como punto de partida de su análisis la contraposición entre el uso de "Imperio inca" o "Tahuantinsuyo", al momento de denominar aquella realidad política que existió en los Andes a partir del siglo XV hasta la conquista española. En nuestro artículo planteamos que, bien lejos de consistir en un mero problema de elección terminológica, esta distinción nos lleva a reconocer los elementos ideológicos que caracterizan las narraciones históricas, en particular en relación a la transmisión de conocimientos en el ámbito escolar.

La necesidad de repensar la enseñanza de la historia latinoamericana se ha planteado con fuerza en los últimos años, ya sea por parte de historiadores (Cibotti, 2016), como por parte de expertos en didáctica (Carretero, 2007). Esta urgencia de cambio ha sido inducida tanto por factores externos al campo académico como por la emergencia de las demandas de actores sociales, entendidos un tiempo como subalternos -por ejemplo, los movimientos indígenas y afrodescendientes-, y la crisis del estado-nación (Rodríguez Ledesma, 2012). Pero, esta necesidad de cambio también ha sido alimentada por corrientes académicas que, en América Latina, ya desde vario tiempo han ido transformando profundamente las ciencias sociales en sentido decolonial y de la revalorización de otros tipos de epistemologías y saberes (Walsh, 2013). Esta convergencia de instancias cuestiona la pervivencia de esquemas interpretativos de origen eurocéntrico en la historia latinoamericana, y particularmente en la de tipo escolar.

En el ámbito de emisión tradicional -hegemónica- de narrativas históricas, el hecho de que la construcción del pasado escolar sea funcional a la legitimación de una visión y de un dominio "occidental" ha sido puesta en evidencia en América Latina por numerosos autores. Gruzinski (2017) ha reconstruido recientemente cómo la historia del Nuevo Mundo, que convencionalmente narramos y estudiamos, es el resultado de una operación historiográfica de matriz teleológico-cristiana que necesitaba trazar una linealidad de tipo finalista. Es de esta concepción teleológico-cristiana, que América parece estar 
poblada de "gente sin historia" hasta la fecha canónica de 1492, y solo después del contacto con Europa los pueblos americanos se configuran como sujeto histórico, aunque subalterno. Pease (1995) denuncia que, la mayoría de los conceptos utilizados en el léxico común de la historia provienen de las traducciones semánticas, no siempre correctas, que los cronistas de Indias pusieron en acto. La perspectiva de observación euro-céntrica respecto al "otro" -ya evidenciada por Todorov (1987) respecto a Cristóbal Colón- hizo que "la imaginación de los cronistas no fue estimulada para producir novedades y [...] reconocieron muchas realidades antes de conocer lo que estaban observando" (Pease, 1995: 105). Esto ha originado un etnocentrismo conceptual (Conrad, 2017) del que la narración histórica debe liberarse a favor de nuevas maneras de expresarse más acordes a los fenómenos estudiados.

Un ejemplo de esta visión histórica etnocéntrica de matriz occidental es justo el hecho de que el Tahuantinsuyo es comúnmente denominado desde la conquista como "imperio incaico", pues los cronistas lo interpretaban a través de la experiencia histórica -para ellos más conocida- del imperio romano o del imperio de Carlos V. Esta adopción de un modelo "imperial" de matriz occidental en la descripción del Tahuantinsuyo ha llevado a describirlo, como veremos en los ejemplos de los currículos y libros de texto ecuatorianos, como una monarquía autoritaria y teocrática, fundada sobre un estado centralista. Este tipo de descripción ha sido históricamente predominante $y$, como veremos, es la que hoy encontramos en los textos escolares. Las investigaciones etnohistóricas han sacado a la luz, en cambio, que la estructura política del Tahuantinsuyo se presentaba de manera bastante diferente a estos modelos: si bien el tema aún es objeto de debates, parece probable que el Tahuantinsuyo no fue una monarquía sino, como mínimo, una diarquía en donde el poder se repartía y equilibraba entre diversas figuras, y donde el acceso a los cargos de poder no seguía necesariamente una línea de sucesión hereditaria. El debate etnohistórico va también en la dirección de pensar que, más bien que ser un estado imperial centralizado, como lo vieron los españoles, el Tahuantinsuyo se parecía más a una federación de jefaturas, fundadas sobre principios de reciprocidad asimétrica. No extraña por lo tanto que varios autores, como por ejemplo María Rostworowski citada en el epígrafe de este artículo (1988), hayan abandonado deliberadamente la terminología de "imperio".

Por lo tanto, a partir de este ejemplo de visión histórica eurocéntrica, el propósito de este artículo es explorar las relaciones y contradicciones entre la historia escolar y la etnohistoria -vista esta última como aquella perspectiva de investigación histórica que ha propuesto visiones y narrativas alternativas sobre América Latina y ha contribuido a "deconstruir discursos colonialistas, orientalistas y/o nacionalistas" sobre los Andes (Ávila Molero, 2010). Concentrándonos sobre un caso específico -el trato dado a la singularidad política histórica andina en los currículos y los libros de texto de Estudios Sociales e Historia en Ecuador- queremos examinar de qué manera los aportes de la investigación etnohistórica -en términos de nuevas visiones e interpretaciones sobre el pasado americano- han sido recibidos o no por la historia escolar y, a partir de ello, interrogarnos sobre cuál es el significado ideológico de la historia que se pretende enseñar hoy en los colegios. 


\section{Perspectivas teóricas: la construcción social del pasado y la historia escolar}

La idea de que la historia no puede considerarse como una verdad totalmente objetiva, sino como una construcción que se realiza desde un determinado contexto socio-cultural y político aparece en la escuela francesa en los años treinta del siglo XX, gracias a las obras de Bloch (2001), y es desarrollada de manera decisiva por Benjamin (2008) quien, aplicando esquemas marxistas, define la historia como un producto de las clases dominantes y pone el tema de la construcción del relato histórico en estrecha conexión con la lucha de clases entre dominantes y dominados. En los años siguientes De Certeau (1975) explora la dimensión textual de la investigación histórica, sosteniendo que "hacer historia" está estrechamente conectado a la práctica de la escritura, y que la escritura responde a elecciones y selecciones argumentativas en conexión con el contexto social y político.

Según De Certeau la razón de ser del pasado se encuentra de manera inevitable en la voluntad del presente. Pero, para el filósofo francés, este "pasado" no es absoluto, ni tampoco puede llegar a ser conocido de forma neutral o verdadera. El "pasado" es una construcción cultural presente en "Occidente", fruto de un segundo tipo de ruptura: la ruptura entre "lo que puede ser 'comprendido' y lo que debe de ser olvidado para obtener la representación de una inteligibilidad presente" (De Certeau, 1975: 10). Para entender y fundamentar el presente, la sociedad occidental se funda en la escritura histórica. Pero, contrariamente a cuanto sostienen las perspectivas positivistas, este tipo de escritura, nos dice De Certeau: "no está interesado por una 'verdad' que hace falta encontrar". La escritura histórica occidental "fabrica 'escenarios' susceptibles de organizar prácticas al interior de un discurso inteligible al día de hoy" (De Certeau, 1975: 13).

En la misma perspectiva y en relación con al ámbito educativo, Ferro (1981) considera a la escuela como uno de los ámbitos de control y reproducción de este pasado desde la infancia, y atribuye la construcción de este pasado escolar a los intereses de los varios tipos de élites y poderes, en función de su afán de legitimar situaciones de dominio. También Florescano (2000 y 2012) considera que la enseñanza de la historia es un "instrumento de educación política", indispensable para forjar al ciudadano contemporáneo, aunque apunta a una educación que refuerce una sociedad libre y democrática.

Aunque es verdad que el Estado, en tanto ente planificador y regulador del sistema educativo, impone contenidos y directrices que bien calzan al concepto de hegemonía, las escuelas no son meras receptoras pasivas ni reproductoras fieles del conocimiento que les llega desde arriba. En este sentido, Rockwell (1986) señala los límites del concepto de reproducción -tan querido a Bourdieu y Althusser- pues este puede velar la mirada sobre los procesos de "reproducción subordinada" (Rockwell, 1986: 12) a través de los cuales formas y contenidos subalternos persisten por encima de los proyectos homogeneizantes. En su extremo -sin llegar a desechar por completo su valor heurístico- la noción tradicional de hegemonía parte de una dinámica unidireccional y mecanicista, "como si entre los educadores y los educandos no pudieran producirse procesos de resistencia ante las normas provenientes de las altas instancias" (Del Pozo, 2008: 28). Más aún, los conceptos -de tradición francesade "cultura escolar" (Julia, 1995; Chervel, 1988) y "transposición didáctica" (Chevallard, 1985) demuestran que los contenidos, los saberes, las prácticas y 
los ritos escolares tienen una fuerte autonomía constitutiva con la que logran sortear la pretendida verticalidad de la reproducción mecánica.

Lo expuesto ayuda a entender la esfera de recepción del discurso histórico de los textos escolares -cosa que escapa a los límites de este artículo. La esfera de la emisión, en cambio, se refleja en el contenido discursivo de los textos. En todo caso, bien vale la pena subrayar que, dentro de la cultura escolar, la enseñanza de la historia suele tener un claro propósito: la persuasión identitaria por la pertenencia nacional y, de la mano con ello, la formación de "virtudes cívicas". Carretero (2007) manifiesta que este es un fenómeno que se presenta con particular fuerza en Latinoamérica pues la devoción a la patria hace parte de los valores prácticamente incontestables.

En tal sentido, Carretero sostiene que los fines persuasivo-identitarios de la historia escolar (historia enseñada, en términos de Chevalard) la mantienen anacrónicamente anclada al romanticismo, corriente filosófica y estética que, como es bien sabido, fue tributaria de primera línea de la ideología nacionalista. La historia académica -historia sabia-, al contrario, desde mediados del siglo XX se muestra más abierta a la discusión y la crítica, lo que la emparenta -a decir de Carretero- con la tradición ilustrada. De ahí que, haciendo operativo el paradigma de la transposición didáctica, la historia escolar se muestra más reacia a adoptar los contenidos de la historia sabia, si estos llegan a poner en cuestión las grandes narrativas con las que se construyeron los imaginarios de la identidad nacional. En este sentido, los relatos de imperios y emperadores, de realezas y todo su decorado dinástico, son elementos que calzan bien con la sensibilidad romántica por cuanto magnifican las identidades nacionales.

En el ámbito de recepción escolar de los discursos de los manuales, este tipo de relatos han sido explorados ya por diferentes estudios. La obra pionera de Marc Ferro (1981) introdujo el análisis de los manuales de historia como representación de los discursos ideológicos de cada estado nacional, afianzando el tema de la historia como narración, y dando importancia al estudio de las estrategias discursivas a través de las cuales se va construyendo el relato histórico escolar. En años recientes, esta perspectiva de estudio se ha ido consolidando en varios países, en relación también a las perspectivas de estudio de análisis crítico del discurso (Atienza, 2006). En el ámbito latinoamericano, tenemos interesantes ejemplos de estudios sobre el trato que los manuales escolares de historia dan a los indígenas (Marimán y Flórez, 1996; Campos Pérez, 2010; Cerón Rengifo, 2015) y a los afrodescendientes (Crestani, 2003; Granda Merchán, 2003; Soler Castillo, 2008; Brito Román y Gámez Ceruelo, 2019), también a eventos más recientes como las guerras del siglo XIX (Chaupis Torres, 2015) y las dictaduras del siglo XX (Morgado Fernández y Fernández-Silva, 2018). Es en esta línea de estudios, que considera los textos escolares como reproductores de elementos ideológicos a través de sus construcciones narrativas y elecciones lexicales, que se inserta nuestro análisis de caso sobre el trato dado al Tahuantinsuyo en los currículos y manuales escolares ecuatorianos.

\section{El currículo y los libros de texto ecuatorianos de historia: un análisis de caso}

El caso de Ecuador es interesante para una profundización, pues este país andino ha vivido en las últimas décadas unos procesos políticos y educativos importantes. La transformación de la educación ecuatoriana empieza en la década de 1980 con la instauración del sistema de Educación Intercultural 
Bilingüe (EIB), que refleja el nuevo protagonismo asumido por los movimientos sociales y políticos indígenas en el país. La reivindicación de la interculturalidad en la educación se convierte a partir de esa década en uno de los elementos-guía de las políticas educativas, y de las reformas que se van sucediendo durante finales del siglo XX e inicios XXI.

El escenario que tomaremos en consideración en el ámbito de nuestro análisis es el que se crea a partir de 2006, con los gobiernos de la denominada "Revolución Ciudadana". ${ }^{1}$ La Constitución de 2008 prevé explícitamente la interculturalidad de la educación, así como la Ley Orgánica de Educación Intercultural (LOEI) de 2011 pone las bases para una serie de reformas siguientes de todo el sistema escolar, desde su organización hasta sus planes de estudio. El sistema educativo que se crea en Ecuador a partir de la LOEI se compone de dos niveles de estudio: la Educación General Básica (EGB), que dura nueve años y se articula en tres subniveles -elemental, media y superior-, y el Bachillerato General Unificado (BGU), que dura tres años. La misma LOEI introduce una reforma del Sistema de Educación Intercultural Bilingüe (SEIB), que es incluido dentro del Sistema Nacional de Educación (SNE), y que es implementado en 2013 con la aprobación del Modelo del Sistema de Educación Intercultural Bilingüe (MOSEIB). El MOSEIB introduce una serie de niveles dentro del SEIB que corresponden a los subniveles del SNE en EGB y BGU. ${ }^{2}$

A partir de esta época aumenta la dimensión técnico-pedagógica de la planificación escolar, a través de la introducción efectiva del currículo como guía de la acción de los docentes. En el marco de la enseñanza de la historia, la reflexión pedagógica aumenta su importancia respecto al pasado, y esto se refleja claramente en el Currículo de EGB y BGU - Ciencias Sociales, aprobado en 2016 por el Ministerio de Educación (MinEduc), y en la estructuración de varios libros de texto contemporáneos, oficiales y no oficiales que, supuestamente, deben seguir sus indicaciones. En el ámbito del SEIB, tenemos la aprobación en 2017 de los catorce currículos de las diferentes nacionalidades, y de una Ampliación curricular para el BGU Intercultural Bilingüe.

El panorama ecuatoriano actual se caracteriza, por lo tanto, por ser la última etapa de un proceso de reformas legislativas y curriculares que, supuestamente, tendría que haber llevado a la definición de nuevas propuestas educativas en sentido intercultural, así como a la creación de nuevos textos que interpretaran de manera diferente estas perspectivas. En relación a nuestros intereses de estudio, puede por lo tanto ser interesante intentar ver de qué manera las nuevas prescripciones curriculares, y los textos que de ellas derivan, se relacionan con la necesidad de un cambio en la enseñanza de la historia y de las ciencias sociales, y con la reformulación de conceptos y fenómenos desde un punto de vista no eurocéntrico.

Pasaremos entonces ahora a describir en específico las fuentes sobre las que fundamos nuestro análisis: los currículos del SNE y de EIB, y los libros de texto de historia.

\section{El currículo nacional de 2016}

El Currículo de EGB y BGU - Ciencias Sociales es el principal texto normativo que tomaremos en consideración, ya que tiene aplicación a nivel nacional y, en realidad, determina la construcción de los textos escolares ecuatorianos. Este currículo introduce una estructura basada en objetivos de aprendizaje y bloques curriculares - 1 . Historia e Identidad; 2 . Los seres humanos en el
1. Con esta denominación nos referimos al periodo de los gobiernos de Rafael Correa (2006-2017) en Ecuador.

2. Los niveles del SEIB introducidos por el MOSEIB son: IPS (Inserción en procesos semióticos), que corresponde al primer año de EGB en el SNE; FCAP (Fortalecimiento cognitivo, afectivo y psicomotriz), que corresponde a los siguientes años del subnivel de EGB elemental en el SNE; DDTE (Desarrollo de destrezas y técnicas de estudio), que corresponde al subnivel de EGB media en el SNE; PAI (Procesos de aprendizaje investigativo), que corresponde al subnivel de EGB superior en el SNE; finalmente, el BGU de EIB, que corresponde al BGU del SNE. 
espacio; 3. La convivencia-, a partir de los cuales se desglosan todos los criterios de evaluación, estructurados en apartados que pueden ser entendidos como unidades didácticas. En el marco de los aprendizajes se da una fuerte importancia al logro de competencias por parte del estudiante, denominadas por el Currículo como "destrezas con criterios de desempeño", siendo estas destrezas las que permiten articular los temas, conceptos y contenidos de Historia.

En concreto, estos contenidos de historia son tratados en el área de conocimiento de Ciencias Sociales, que en EGB se compone de una sola asignatura, denominada "Estudios Sociales". Esta asignatura tiene una carga horaria complexiva de dos horas semanales en EGB elemental, tres horas en EGB media y cuatro en EGB superior. En BGU, el área de Ciencias Sociales se diferencia en tres asignaturas que son: Historia, Filosofía y Educación para la Ciudadanía. La asignatura de Historia tiene una carga horaria de tres horas semanales los primeros dos cursos, y de dos horas el tercero.

Los temas de historia son tratados en EGB en el primer bloque de la asignatura de Estudios Sociales -Historia e identidad-, pero de manera diferente en los tres subniveles. En el primero -cursos de $1^{\mathrm{o}}$ a $4^{\mathrm{o}}$ - se introducen temas de historia ligados a la identidad personal, familiar y de la comunidad y localidad del estudiante. En el subnivel de EGB media -cursos de $5^{\circ}$ a $7^{\circ}$ - se introducen contenidos centrados en la historia nacional ecuatoriana, que van desde las culturas aborígenes del Ecuador al siglo XXI. En el subnivel de EGB superior -cursos de $8^{\circ}$ a $10^{\circ}$ - se retoman los contenidos según una idea de "historia universal", que va desde la prehistoria de la humanidad a la contemporaneidad global, aunque el acento se pone en la región latinoamericana. En BGU, la asignatura de Historia retoma la perspectiva de la "historia universal", y los temas tratados vuelven a comenzar con la prehistoria y las antiguas civilizaciones de Oriente Medio, para de nuevo finalizar en la contemporaneidad del siglo XXI.

En relación a los temas de historia pre-hispánica, vemos, por lo tanto, cómo los estudiantes los encuentran en tres momentos diferentes -los subniveles de EGB media y superior, y en BGU- según la perspectiva didáctica del "rizoma", que prevé un regreso progresivo sobre los mismos temas para irlos tratando cada vez según un nivel de análisis más elaborado. Cabe señalar que, en el caso del Currículo ecuatoriano el aumento de complejidad que se propone incide en el paso de lo nacional hacia lo mundial o, en términos más específicos, de lo local hacia lo global. Esta interpretación del rizoma parece algo discutible pues deja en un nivel de menor elaboración conceptual toda una serie de temas más ligados a la historia ecuatoriana que son considerados "locales" y, por tanto, no se retoman en EGB superior y en BGU, imposibilitando que el estudiante pueda establecer una conexión entre niveles de análisis que permitan entender la multi-dimensionalidad de los fenómenos históricos. Este es, por ejemplo, el caso de los señoríos étnicos pre-incaicos en Ecuador, que son objeto

3. Varios elementos hacen sospechar que los fundamentos del currículo han sido redactados, sobre todo, por especialistas de pedagogía y didáctica y que no han sido revisados a fondo por especialistas en Historia o Ciencias Sociales. Esto explica ciertas incoherencias teóricas -como la interpretación del rizoma recién expuesta- así como, la ausencia de referencias a cualquier otro teórico de la historia -con excepción de los clásicos Engels y Bloch- en marcada desproporción a las referencias atribuidas a los especialistas de didácticas aplicadas a las ciencias sociales. de consideración sólo en EGB media y después no vuelven a ser tratados. ${ }^{3}$

\section{Los currículos de EIB de 2017}

En el ámbito de la SEIB, tomaremos en consideración el currículo de la nacionalidad kichwa, por ser el más usado entre los de pueblos y nacionalidades, así como el más cercano a los temas que vamos a tratar. El Currículo nacional kichwa intercultural bilingüe de EGB - Ishkayshimikawsaypurakichwamamallaktayukkunapayachayñan es relativo a los niveles que el SNE equivalen a EGB. Este currículo, de acuerdo al MOSEIB, no presenta una división disciplinar sino que está compuesto por 75 unidades integradas de aprendizaje, en las que se integran diferentes 
campos de conocimiento que van regresando de manera cíclica. No es posible, por lo tanto, encontrar en este currículo un área específica de ciencias sociales o historia, con relativa carga horaria, indicación de objetivos y destrezas, pues los temas históricos están presentes en todas las unidades de manera diferente. Por ejemplo, encontramos temas relativos a la historia inca en las unidades 38 -"Época de cosecha"- 1ํaño de DDTE, 5ํ de EGB Media-, 62 -"Periodo colonial"-, 65 -"Historia de América 1492-1830"- ambas de 3oaño de PAI, 9o de EGB Superior. Es curioso que la Unidad 66 -"Periodo prehispánico"- no trate temas ligados al mundo inca.

En el nivel de Bachillerato, el SEIB y el SNE no se diferencian demasiado. Si bien la Ampliación curricular para el BGU Intercultural Bilingüe introduce en el área de Ciencias Sociales una serie de declaraciones programáticas que lo diferencian del Currículo de EGB y BGU - Ciencias Sociales, y también se cambia la denominación de la asignatura a "Historia y Etnohistoria", en realidad toda la estructura y contenidos se corresponden. Las únicas diferencias entre los dos documentos -y, por ende, entre las asignaturas de "Historia" y de "Historia y Etnohistoria"- se encuentran en los apartados de introducción de la asignatura, de contribución de la misma a los perfiles de salida, y en los fundamentos epistemológicos, disciplinares y pedagógicos. Por lo demás, los bloques curriculares, ejes temáticos, objetivos y destrezas son idénticos, con la excepción de la introducción de un $11^{\circ}$ objetivo general sobre la valoración de las culturas ancestrales pero que no es desarrollado en ninguna parte.

\section{Los textos escolares}

En Ecuador los libros de texto son una iniciativa de editoriales privadas que compiten entre ellas para el acceso al mercado editorial. Las unidades educativas públicas utilizan a nivel nacional un mismo texto, seleccionado por el Ministerio de Educación en un concurso plurianual entre las editoriales a partir de 2007, y que se distribuye gratuitamente a sus estudiantes. Las unidades educativas privadas son libres de elegir sus textos entre los que circulan en el mercado, y que hayan recibido una certificación curricular por parte del Ministerio. La diferencia entre los dos tipos de textos es, por lo tanto, su grado de difusión en los colegios del país. Hay que precisar que, por lo menos en relación a la historia y a las ciencias sociales, los textos que existen en el país son publicados en función del SNE, y reciben la certificación en base al Currículo de EGB y BGU - Ciencias Sociales. No existen textos específicos de historia o ciencias sociales para el SEIB, por lo que en las unidades educativas de EIB se usan normalmente textos concebidos sobre la base del currículo nacional. Esto resta eficacia a los currículos específicos de EIB, sea a nivel de EGB que de BGU, pues sus docentes no disponen de material propio para poder implementarlos (Rodríguez Cruz, 2018).

Para nuestro estudio, hemos tomado en consideración un total de diez libros de texto, pertenecientes a cuatro editoriales diferentes presentes a nivel nacional (Tabla 1). De estos textos, tres son de EGB media, cuatro de EGB superior y tres de Bachillerato. Dentro de la serie de volúmenes que cada editorial produce para cada nivel, los que hemos tomado en consideración son los que tratan contenidos relativos al Tahuantinsuyo: el volumen 5 para EGB media, el volumen 8 o 9 para EGB superior, y el volumen 1 o 3 para BGU. Se han considerado los libros que el Ministerio de Educación ha seleccionado para su adopción en las unidades educativas públicas, como los no adoptados pues estos pueden ser utilizados en las unidades educativas privadas. 
4. En otro trabajo, un autor de textos identificado, Enrique Ayala Mora, refiere que a partir de la década de 1970, la producción de libros de texto se delegó a maestros con poca formación "que publicaron libros por necesidad de la enseñanza o como un negocio particular" (Ayala Mora, 2015: 132). Estos textos fueron reeditados hasta finales del siglo XX, cuando empezaron a considerarse obsoletos y fueron reemplazados con manuales más adecuados, no obstante algunos fueron actualizados "con igual mala calidad” (Ayala Mora, 2015: 135).
La dimensión comercial del libro de texto determina que exista una dificultad de reconstruir el proceso editorial, así como atribuir responsabilidades de autoría específicas. Los textos presentan en efecto toda una serie de aparatos -iconografía, tablas, profundizaciones, ejercicios, etc.- que son producto de un trabajo editorial colateral no siempre reconocible. En la mitad de los textos que hemos considerado -textos 3, 6, 7, 9 y 10-, los autores mencionados son presentados solo como "autores de contenidos", y en tres casos -textos 2, 5 y 8- no se mencionan autores. Solo en dos ocasiones -textos 1 y 4 - la autoría atribuida es plena, y los autores son académicos conocidos en el contexto nacional, aunque cabe decir que tales libros son la re-edición de libros publicados por primera vez en la década de $1990 .{ }^{4}$ Por lo tanto, en ninguno de los casos tenemos la certeza o de quiénes son los autores o de cuál es su preciso control sobre el producto final. En nuestra investigación, por lo tanto, consideraremos cada texto como un producto colectivo y en parte impersonal, cuya responsabilidad final es de la editorial que lo publica.

\begin{tabular}{|c|c|c|}
\hline Niveles & $\begin{array}{l}\text { Textos adoptados por el } \\
\text { Ministerio de Educación }\end{array}$ & $\begin{array}{l}\text { Textos no adoptados por el } \\
\text { Ministerio de Educación }\end{array}$ \\
\hline \multirow{2}{*}{$\begin{array}{l}\text { Educación General } \\
\text { Básica media }\end{array}$} & \multirow{2}{*}{$\begin{array}{l}\text { [1] Ayala Mora, Enrique (2017). } \\
\text { Estudios sociales. Corporación } \\
\text { Editora Nacional. } \\
\text { Vol. } 5 .\end{array}$} & $\begin{array}{l}\text { [2] S/a, (2016). Estudios sociales. Editorial } \\
\text { Don Bosco. Vol. 5. }\end{array}$ \\
\hline & & $\begin{array}{l}\text { [3] Vacas Andrade, Daniela (2017). Talento } \\
\text { en sociales. Edinun. Vol. } 5 \text {. }\end{array}$ \\
\hline \multirow{3}{*}{$\begin{array}{l}\text { Educación General } \\
\text { Básica superior }\end{array}$} & \multirow{3}{*}{$\begin{array}{l}\text { [4] Ayala Mora, Enrique y } \\
\text { Gonzalo Ortiz Crespo (2017). } \\
\text { Estudios sociales. Corporación } \\
\text { Editora Nacional. Vol. } 8 .\end{array}$} & $\begin{array}{l}\text { [5] S/a, (2016). Estudios sociales. Editorial } \\
\text { Don Bosco. Vol. } 9 .\end{array}$ \\
\hline & & $\begin{array}{l}\text { [6] Villa, Karla y Christian Espín (2018). } \\
\text { Ciencias sociales. Editorial Educatemas. } \\
\text { Vol. } 8\end{array}$ \\
\hline & & $\begin{array}{l}\text { [7] Zhingre, Raúl. (2018). Talento en } \\
\text { sociales. Quito, Edinun. Vol. } 8\end{array}$ \\
\hline \multirow{2}{*}{$\begin{array}{l}\text { Bachillerato } \\
\text { General Unificado }\end{array}$} & \multirow[t]{2}{*}{$\begin{array}{l}\text { [8] S/a, (2017). Historia. } \\
\text { Editorial Don Bosco. Vol. } 3\end{array}$} & $\begin{array}{l}\text { [9] Villacreses, Xavier (2017). Historia. } \\
\text { Editorial Educatemas. Vol. } 1\end{array}$ \\
\hline & & $\begin{array}{l}\text { [10] Byron Castro, Historia, 2018, Quito, } \\
\text { Edinun. Vol. } 1\end{array}$ \\
\hline
\end{tabular}

Tabla 1. Textos escolares ecuatorianos del período 2016-2019, considerados en el artículo. Fuente: elaboración propia.

\section{Consideraciones metodológicas}

El tema propuesto -el trato dado a la singularidad histórica andina- ha sido investigado con los métodos propios del análisis del discurso, es decir examinando en cada texto las partes relativas a la historia política inca desde el punto de vista del enunciado, del léxico específico usado, pero también de los aparatos iconográficos de apoyo. Estos elementos discursivos han sido sucesivamente analizados como transmisores de ideologías específicas (Atienza Cerezo, 2006) en función de la construcción de narraciones históricas diferentes (Ferro, 1981). En nuestro análisis, hemos prestado particular atención a la selección terminológica de cada texto, según la idea de que los términos remiten a conceptos ideológicos que revelan también el posicionamiento del texto (Morgado Fernández y Fernández-Silva, 2018) y, en consecuencia, al contexto de enunciación desde el cual este se produce (Soler Castillo, 2008).

Estudiar los currículos y los libros de texto es un ejercicio investigativo que puede presentar al mismo tiempo potencialidades y límites. Según Carretero, "el análisis comparativo de los libros de texto constituye una vía posible para comprender el proceso de legitimación del conocimiento en la escuela" (2007: 
76). Para Carretero el texto es la primera concreción del currículo y, por lo tanto, el mediador entre el conocimiento oficial y el estudiante que, a través de la interiorización de sus contenidos, va construyendo la realidad. Otros autores son más cautos y ponen en guardia de los posibles límites al momento de abordar el libro de texto como evidencia histórica. Choppin (2008) recuerda que son el producto de un proceso editorial e intelectual que debe ser siempre contextualizado, y que su clasificación y tipología puede variar fuertemente según el tiempo y el espacio donde son producidos. De Cock (2018) recuerda que los libros de texto son, ante todo, productos comerciales y su producción es competencia de editoriales privadas, señalando la dificultad de valorar la práctica de la que son en realidad objeto por parte de los docentes, así como su incidencia e influencia sobre el alumnado. El análisis textual del libro no refleja el uso que efectivamente se hace de él. En este sentido, Carretero también reconoce que es "el análisis de la interacción en el aula junto con el de los libros de texto" lo que "permite acceder a los aspectos más dinámicos de la práctica escolar: el modo en que los planes, los programas y los objetivos diseñados por las políticas educativas son recibidos, resistidos y/o resignificados en la cotidianidad por los destinatarios es decir, los alumnos y los docentes" (2007: 76).

Respecto a este importante problema del estudio del libro de texto -la dificultad de valorar su práctica-, nuestra investigación asume esta constatación, limitándose nuestro análisis a considerar el texto como una guía que produce un imaginario colectivo, un repertorio de informaciones enmarcado en un horizonte de saber dentro del cual docentes y estudiantes se van moviendo (Rockwell, 1995). En este sentido, el libro de texto -pero también el currículoreproduce más la dimensión que Valls Montés (2001) define como la "historia deseada", diferente de la "historia enseñada" y de la "historia aprendida". Si consideramos que el texto es un productor de imaginarios sociales y colectivos podemos coincidir con Carretero en que "contiene llaves y peligros, pues en sus páginas hay palabras que se presentan como las claves para construir el 'mundo"', y que tiene el "poder para cartografiar lo real en el sentido amplio, discriminándolo de la fantasía y recortando aquello que se dará por cognoscible, por lógico y legible" (2007: 79).

Por lo tanto, en los párrafos siguientes usaremos los currículos y los libros de texto como elementos al mismo tiempo productores, transmisores y replicadores de determinados imaginarios sobre el pasado y su interpretación, que no deben asumirse de manera neutral, sino como reflejo de narraciones históricas que, inevitablemente, tienen una dimensión social y política.

\section{Los puntos de análisis: la experiencia política andina}

Pasamos ahora a examinar como el Currículo y los diferentes textos escolares ecuatorianos tratan el tema de la organización política del Tahuantinsuyo, y contrastaremos la narración escolar con las que han sido las propuestas y aportes elaborados por la investigación etnohistórica. Para hacerlo, nos fijaremos sobre una serie de temas que presentan opciones interpretativas alternativas entre ellas, cuya elección puede dar como resultados imágenes diferentes de la organización social y política de los Incas.

Como fuera adelantado desde el principio del artículo, la reflexión que proponemos es a partir del uso de la palabra "imperio" y de sus derivados -el 
Sapa Inca como "emperador"- difundida prácticamente en todos los textos examinados.

Este uso se origina parcialmente en los currículos, que presentan una oscilación entre las varias terminologías posibles (Tabla 2). El Currículo de EGB y BGU - Ciencias Sociales, usa en el nivel de EGB tres términos para definir al conjunto político incaico: Imperio Inca, Incario, y Tahuantinsuyo. En una de las destrezas indicadas en el Bloque "Historia e Identidad" de EGB Media se cita: "Explicar las características de la dominación incaica en el Ecuador, la organización de su imperio y de su sociedad" (CS.3.1.4), mientras que en otra se habla de "crisis del incario" (CS. 3.1.5). En EGB Superior, de nuevo una de las destrezas (CS.4.1.20) es "Analizar el origen y desarrollo del Imperio Inca como civilización y la influencia de su aparato político y militar", pero en la siguiente (CS.4.1.21), "Describir la estructura organizativa del Tahuantinsuyo y la organización social para reproducirla y participar en ella", ya se usa el término propio.

En el Currículo nacional Kichwa, es interesante ver el uso de las terminologías desde su componente de bilingüismo. En el texto del currículo en idioma kichwa, se usan tres términos diferentes: "Ñawpa Inca runakuna" (U38), que podría traducirse como "antiguo pueblo inca"; "Incakuna" (U38), es decir simplemente "los Incas"; "Tawantinsuyu”, es decir "Tahuantinsuyo". Es significativo que, en cambio, en la versión castellana del currículo, en los objetivos y destrezas en los que se citan estos términos, se usan los equivalentes del Currículo de EGB: los dos primeros son traducidos con el término "Incario", mientras que para "Tawantinsuyu", siempre se especifica este término como equivalente de "Imperio Inca". Es más, en la Unidad 62 se lo denomina como "Imperio Inca 'Tahwantinsuyu'", como si este fuera el nombre del imperio específico y no una categoría política autónoma.

Finalmente, en BGU, en ambos documentos curriculares del SNE y del SEIB, ni los objetivos ni las destrezas dan una orientación terminológica pues se usa solo la expresión: "culturas aborígenes de América Latina precolombina (mayas, aztecas e incas)" (CS.H.5.3.1).

\begin{tabular}{|c|l|l|}
\hline Nivel & \multicolumn{1}{|c|}{$\begin{array}{c}\text { Currículo del Sistema Nacional } \\
\text { de Educación (SNE), 2016 }\end{array}$} & \multicolumn{1}{|c|}{$\begin{array}{c}\text { Currículo del Sistema de Educación } \\
\text { Intercultural Bilingüe (SEIB) Kichwa, } \\
\text { 2017 }\end{array}$} \\
\hline EGB media & CS.3.1.4: Imperio Inca CS.3.1.5: Incario & $\begin{array}{l}\text { U38: Nawpa Inca runakuna (Incario) } \\
\text { U38: Incakuna (Incario) }\end{array}$ \\
\hline EGB superior & $\begin{array}{l}\text { CS.4.1.20: Imperio Inca } \\
\text { CS.4.1.25: Tahuantinsuyo }\end{array}$ & $\begin{array}{l}\text { U62: Tawantinsuyu (Tahuantinsuyo o } \\
\text { Imperio Incaico) } \\
\text { U62: “Tawantinsuyu” (Imperio Incaico } \\
\text { "Tawantinsuyu") }\end{array}$ \\
\hline BGU & \multicolumn{2}{|c|}{ CS.H.5.3.1: Incas } \\
\hline
\end{tabular}

Tabla 2. Denominaciones del Tahuantinsuyo en los currículos ecuatorianos del SNE y del SEIB Kichwa. Fuente: elaboración propia.

A partir de este marco terminológico curricular, los libros de texto optan por usar mayoritariamente la expresión "imperio inca", y consecuentemente definen al Sapa Inca como "Inca emperador". Los más explícitos son los textos firmados por Ayala Mora, que son también los textos adoptados por el Ministerio de Educación en EGB Media y Superior. ${ }^{5}$ Si bien en los títulos de los capítulos se alternan las tres denominaciones de "Incario" (texto 1), "Tahuantinsuyo" (Texto 4) e "Imperio inca" (textos 1 y 4), estos volúmenes son los que describen,
5. A pesar de la diferencia de nivel estos textos son muy similares $y$, a diferencia de los demás libros de otras editoriales, replican los mismos contenidos; por ejemplo: las pp. 21-23 del texto 1 corresponden integralmente a las pp. 107-109 del texto 4 . 
con más contundencia, al Inca como un emperador con plenos poderes, hablando de "imperio centralizado y autocrático" (texto 1: 22; texto 4: 108). La idea del autoritarismo es reforzada en los aparatos de ejercicios, donde en un ejercicio de reflexión activa se pregunta: “¿Qué tipo de poder creen ustedes que ejercía el Inca o emperador del Tahuantinsuyo si era considerado un dios?" (texto 1: 22). Cuando se describe el funcionamiento del Tahuantinsuyo, se escribe: "Tenía a su mando a un jefe ejecutivo del Estado y un consejo de nobles, presidido por un sumo sacerdote, que reemplazaba al inca en su ausencia. Los jefes (curacas) de cada provincia tenían cierta autonomía en asuntos locales, pero su mandato no podía contravenir al Inca" (texto 4: 102).

Los demás textos, no adoptados por el Ministerio de Educación en EGB Media (textos 2 y 3) y Superior (textos 5, 6 y 7), son algo más cautos: hablan de "imperio inca" y definen al Sapa Inca como "emperador" pero no hacen referencia al autoritarismo, con la excepción del texto 6 para EGB Superior, que define al Inca como "soberano poseedor de los territorios y vida de sus súbditos" (texto 6: 166). Un aspecto en el que todos los textos de EGB coinciden es la presencia como figura de una "pirámide jerárquica", en la que se representa la estructura social del Tahuantinsuyo (texto 1: 22; texto 2: 128; texto 3: 162; texto 4: 108; texto 5: 58; texto 6: 67; texto 7: 237). Esta pirámide representa en su vértice al Sapa Inca y es una clara equivalencia de las pirámides feudales que abundan en los textos escolares que tratan de la Edad Media europea.

En BGU la situación es parecida. El texto adoptado por MinEduc habla de un "imperio unificado políticamente y culturalmente" (texto 8: 28), y también los otros textos hablan de imperio (texto 9: 73; texto 10: 97). También en estos textos se presenta la pirámide jerárquica (texto 8: 29; texto 10: 98).

De frente a esta casi unanimidad en la definición del Tahuantinsuyo como un "imperio" y la designación del Sapa Inca como "emperador", cabe preguntarse si estos conceptos son apropiados o no a la descripción e interpretación del fenómeno histórico que se está explicando. Es aquí, por lo tanto, que es interesante introducir un contraste con algunas obras clásicas de la investigación etnohistórica. En los ensayos de Murra (1975) y Rostworowski (1983 y 1988) nunca se usa el término "imperio", sino que se intenta describir la forma política del Tahuantinsuyo desde elementos descriptivos más internos o émicos. Como hace notar Pease (1995), el uso del término "imperio" es una derivación de las crónicas hispanas, que interpretaban la realidad andina con parámetros europeos:

Pocas cosas pueden ser más cuestionables que el traslado de nociones políticas. Los cronistas introdujeron en los Andes imperio, monarquía y rey, por cierto, sus múltiples derivados. Hay estudios que precisan la idea de Roma en la historiografía indiana, pero son las nociones romanas, consideradas ejemplares, las que se emplean en las crónicas. Se sabe que el Inca Garcilaso empleó abundantemente a Julio César y otros autores, pero mucho antes de él, los cronistas -como otros escritores de entonces- utilizaron esquemas romanos (Pease, 1995: 134).

Varios autores consideran este intento de traducción conceptual como una operación típicamente eurocéntrica, a través de la cual categorías descriptivas locales europeas son trasladadas a un plano conceptual más abstracto y general, que las universaliza y las proyecta entonces como categorías analíticas universales de lo "otro" (Spivak, 2010). La interpretación, que los actores sociales -en este caso los primeros cronistas- hacen de lo vivido, es una operación de 
traducción cultural a través de conceptos "cercanos a la experiencia" (Geertz, 1973). En nuestro caso, como hace notar Pease, lo cercano a la experiencia era la idea de Imperio Romano que la Europa pos-renacentista estaba redescubriendo en ese momento, y que servía de modelo ideológico para el gobierno de Carlos V y su aspiración de "monarquía universal" (Gruzinski, 2013).

Pero, ¿qué es lo que se pierde replicando esta operación de traducción conceptual? La investigación etnohistórica nos sugiere algunos temas, que ahora pasaremos en reseña: a. La diarquía y los suyos

\section{a. La diarquía y los suyos}

Son ya numerosos los estudios que han reconstruido como la organización política andina se funda sobre un dualismo del poder. Al nivel de la élite del poder Rostworowski (1983) y Zuidema (1989) han reconstruido como las panakas -linajes nobles de Cusco- se fundaron alrededor de la división entre "mitades". Estas mitades eran al mismo tiempo espaciales y sociales: en el Cusco existía geográficamente la mitad "de arriba" (hanan), y la mitad "de abajo" (hurin), y en ellas habitaban los diferentes linajes descendientes de los principales soberanos. Cada una de las mitades tenía su Inca, y en efecto las crónicas nos reportan la existencia del Sapa Inca, o Inca Hanan, y del Inca Hurin. Estas dos figuras se repartían junto a sus panakas las principales funciones políticas: el Inca Hanan tenía funciones guerreras, mientras que el Inca Hurin tenía funciones religiosas (Rostworowski, 1983: 129; Hernández Astete, 2002). Los cronistas quisieron interpretar esta dualidad como la existencia de un "emperador" y un "sumo sacerdote" pero en realidad ya numerosos autores como Duviols (1980), Rostworowski (1988), Hernández Astete (2002) y Pärssinen (2003) hablan de una efectiva diarquía en Cusco, en la que las dos figuras se equilibraban en la gestión del gobierno. Zuidema (1989) reconstruye también cómo esta dualidad da origen a una cuatripartición de las panakas, y cómo esto lleva a la constitución de los cuatro suyos -partes, regiones- que constituyen el área de dominio de los Incas. En ese sentido, interpretando algunas crónicas, Rostworowski llega a sostener que la forma de gobierno del Tahuantinsuyo -literalmente, los cuatro suyos- fuera un consejo de cuatro Capac -jefes- cada uno a cargo de una región, y que el Sapa Inca fue en realidad solo uno de los cuatro, aunque el principal (1983: 168).

Los cuatro Capac mantenían entre ellos los vínculos ancestrales de la reciprocidad, en un complejo sistema de complementariedad. Este esquema de dominio y de mando es muy distinto de los hábitos de poder europeos y es comprensible que los españoles del siglo XVI no entendieran su articulación, dejando una información deformada, confusa e inexacta (Rostworowski, 1983: 168).

Como hemos visto, los libros de texto ecuatorianos dan una representación completamente diferente que refleja más la visión no filtrada de las principales crónicas que no la de las investigaciones etnohistóricas. ${ }^{6}$ En ellos raramente

6. Aunque la mayoría de las crónicas presentan al Tahuantinsuyo en términos de monarquía, se encuentran alusiones y referencias al sistema dual en autores como Cieza de León, Díez de Betanzos y Guamán Poma de Ayala (Hernández Astete, 2002). se cita al Inca Hurin, y en los pocos casos en los que se hace mención a él -generalmente en la representación de la pirámide jerárquica- es con la definición de "sumo sacerdote" (texto 1: 22; texto 3: 62). Nuevamente la imagen de la pirámide social medieval -en la que el clero se ubica por debajo de la monarquía- interfiere en la interpretación de la organización social del incario. El poder secular y el poder teocrático se presentan escindidos en dos esferas distintas, cuando en realidad en el mundo andino esta relación era más directa. 


\section{b. La sucesión al poder}

Es significativo que, en algunos de los textos escolares, en las representaciones de pirámides jerárquicas se citen, en vez de al Inca Hurin, a la coya y al auqui, definidos como esposa e hijo del Inca (texto 6: 166; texto 8: 29). Estas figuras parecen ser importantes para una visión europea que, de nuevo, interpreta al Tahuantinsuyo como una monarquía hereditaria, según la visión tradicional que tenemos de un "imperio". Esto es explícito, por ejemplo, en el texto del MinEduc para BGU, que habla de "gobierno hereditario teocrático" (texto 8: 28). Si consideramos en cambio los aportes de la etnohistoria, estas dos figuras resultan ser marginales pues parece ser ya consolidado que la sucesión de todo cargo en el Tahuantinsuyo -desde el Inca a los curacas- no fuera de padre a hijo sino al pariente considerado más capaz (Rostworowski 1983; Murra, 1975: 41-82; Zuidema, 1964).

En relación a la estructura dual del poder, la sucesión era gradual, pues los dos Incas, Hanan y Hurin, podían coexistir por muchos años y, en algunos casos, pasar de un cargo a otro. La definición de quién accedía a estas posiciones era extremamente complicada, y a la muerte de cada Inca se verificaban conflictos rituales de cuyo éxito dependía la definición de la diarquía (Regalado de Hurtado, 1993). Si bien el debate aún está en curso entre los historiadores (Hernández Astete, 2012), lo que podemos de toda forma constatar es que su complejidad no se recoge en los libros de texto, que prefieren dar una imagen de monarquía hereditaria y de esta forma ponen siempre en evidencia a la figura del primogénito del Inca Hanan.

\section{c. La dualidad entre los curacas y en el mundo andino}

El reparto de poder entre dos figuras parece haber sido en realidad una característica de todos los niveles de poder en el sistema político incaico. Ya numerosos estudios han evidenciado cómo la división entre mitades hanan y hurin se puede encontrar en otros centros de poder lejanos del Cusco, entre los cuales está la misma Quito (Salomon, 2011), pero también en la organización de comunidades rurales periféricas (Wachtel, 2001). Rostworowski sostiene que la división en mitades y la diarquía de poder era una "antigua costumbre panandina" que seguramente antecedío a la conquista incaica y que se mantuvo, citando nueve casos de señoríos donde el sistema de gobierno era de dos curacas (1983: 111-126). Esta costumbre de compartir el poder llegó a ser tan generalizada que, no solo interesó desde aspectos religiosos o administrativos sino también militares, pues ha sido posible construir como casi todos los ejércitos incas tenían dos jefes (1983: 101-110).

Los textos escolares no citan para nada este modelo dual en el reparto de poder, y dan por sentado que por cada señorío o provincia había un solo curaca. Solo un texto, entre todos, cita la dualidad hanan/ hurin como modelo constitutivo de las ciudades andinas, pero sin ahondar en sus implicaciones políticas (texto 4: 102).

\section{d. la reciprocidad y los intercambios}

Las relaciones entre sujetos en el contexto incaico se fundaban sobre una idea de reciprocidad, que se concretaba en la institución de la mita. La mita precolonial era un mecanismo de reparto del trabajo, por lo que los campesinos dividían su tiempo entre las tierras que les habían sido asignadas, las tierras de los curacas, y las tierras del Inca. En cambio, el Inca otorgaba protección y 
determinados servicios, a través de la construcción de obras públicas -caminos, infraestructuras, etc- (Wachtel, 1973).

Murra (1975) ha evidenciado cómo este tipo de relaciones pueden ser asimilables a un modo de producción pre-capitalista fundado sobre mecanismos de redistribución, al mismo tiempo materiales y simbólicos. Mucho se ha discutido también sobre la existencia de mercados en los Andes prehispánicos (Salomon, 2011), con una general tendencia a considerar que antes de la llegada de los españoles los intercambios fueran más gestionados por los grupos de poder, que no por una lógica de intercambio capitalista. En los intercambios prehispánicos la redistribución y la reciprocidad eran las lógicas más consideradas. Murra en este sentido sostiene que:

en los Andes hubo un intercambio marítimo, de larga distancia, de objetos preciosos [...] cuyo contexto todavía no captamos cabalmente pero cuyo significado todavía queda por aclarar, sin hablar de 'comercio', 'tributo'o 'mercados' que no existieron en los Andes (Murra, 1975: 247).

Estos aspectos son tratados de manera parcial en el currículo y en los textos escolares. En EGB Media y Superior el currículo no contiene objetivos que traten del sistema económico del Tahuantinsuyo, pero en BGU sí encontramos la indicación de la destreza con criterio de desempeño: "Sintetizar los principios de organización e intercambio social (reciprocidad y redistribución) de los pobladores nativos de los Andes, en función de la equidad y justicia social" (CS.H.5.3.6).

Esto hace que en los libros de EGB se mencione poco el tema de los intercambios, pero que en BGU el tema de la reciprocidad se trate en secciones específicas, aunque prácticamente siempre referido a su dimensión horizontal. En este sentido, la mita siempre es definida como "tributo", cuando en realidad correspondía a un sistema generalizado de reciprocidad (Wachtel, 1973). Al respecto, Udo Oberem (1985) refiere que en el incario "la remesa de productos desempeñaba un papel muy pequeño frente a la prestación de ciertos trabajos y por eso algunos etnohistoriadores desechan el concepto de tributo en su aplicación al tiempo incaico" (Oberem, 1985: 166). Antes que tributo, en realidad se trataba de un sistema de reciprocidad en la prestación de trabajos, cuyos frutos eran repartidos dentro de mecanismos de redistribución (Ramón, 1991).

\section{e. La distribución del poder del centro a la periferia}

Ya hemos visto como la aplicación de categorías políticas eurocéntricas por parte de los cronistas causaba no solo interpretaciones equivocadas sino, a veces, también confusión y contradicciones que ellos mismos no sabían cómo resolver (Rostworowski, 1983; Pease, 1995). Esta confusión se transmite a los textos escolares contemporáneos en el momento en que se intenta explicar las relaciones entre élite cusqueña y curacas locales a través de las categorías de centralismo/ descentralismo. La complejidad de estas relaciones hace que los textos escolares oscilen entre las dos interpretaciones.

Un buen grupo de textos escolares coinciden en interpretar que el Tahuantinsuyo era un imperio centralizado. Algunos de los textos utilizan expresamente esta categoría (texto 1: 22; texto 4: 108; texto 5: 57; texto 8: 28 ). Solo en un caso de EGB Superior se sostiene que: "Si bien suponían ser un imperio unificado, el gobierno era descentralizado, es decir que el Cápac Inca nombraba a los gobernadores, quienes le debían su lealtad y eran los encargados de administrar 
cada zona" (texto 6: 167). En la etapa EGB Superior, el texto adoptado por MinEduc siempre sostiene, al mismo tiempo, que el Tahuantinsuyo era un "imperio centralizado" (texto 4: 108), pero también que "los jefes -curacas- de cada provincia tenían una cierta autonomía en asuntos locales" (texto 4: 102).

Una vez más, esta diferencia de interpretaciones nace, a nuestro parecer, de la dificultad de describir la relación centro-periferia con categorías externas, reduciendo el análisis a una clasificación que en los estudios sociales es de origen funcional-estructuralista y que corresponde a una visión ética del fenómeno político. En este sentido, parecería más interesante intentar construir descripciones de las relaciones entre élites y curacas a partir de las categorías locales que, si bien se alejen del léxico politológico europeo, pueden dar una imagen más sofisticada del sistema político inca (Murra, 1975).

En contraposición a la noción centralizadora según la cual el Cusco ejercía un poder centrípeto sobre el Tahuantinsuyo, el antropólogo ecuatoriano Hugo Burgos (1995) llamó la atención sobre la manera en que la expansión del incario realmente adoptó una estrategia centrífuga, por la cual la centralidad del poder se fue desplazando hacia los territorios conquistados. Tomebamba, en un primer momento, y Quito más adelante -al tiempo de la conquista española- fueron los lugares de residencia de los últimos Sapa Inca, y es claro que adquirieron funciones administrativas de capital importancia. Como centros de poder fueron también los bastiones de la expansión septentrional del imperio.

\begin{tabular}{|c|c|c|}
\hline Niveles & $\begin{array}{l}\text { Textos adoptados por el } \\
\text { Ministerio de Educación }\end{array}$ & $\begin{array}{l}\text { Textos no adoptados por el } \\
\text { Ministerio de Educación }\end{array}$ \\
\hline \multirow{2}{*}{$\begin{array}{l}\text { Educación } \\
\text { General } \\
\text { Básica } \\
\text { media }\end{array}$} & \multirow[t]{2}{*}{$\begin{array}{l}1] \text { Imperio centralizado y } \\
\text { autocrático. } \\
\text { Pirámide jerárquica. Inca hurin } \\
\text { como "sumo sacerdote". } \\
\text { Sucesión monarquica. }\end{array}$} & $\begin{array}{l}\text { [2] Imperio. } \\
\text { Pirámide jerárquica. } \\
\text { División en } 4 \text { regiones. } \\
\text { Se considera que había un heredero pero se } \\
\text { dice que la sucesión es electiva. }\end{array}$ \\
\hline & & $\begin{array}{l}\text { [3] Imperio. } \\
\text { Pirámide jerárquica. } \\
\text { División en } 4 \text { regiones. } \\
\text { Inca hurin como "sumo sacerdote", pero } \\
\text { no en la realeza sino en la "nobleza de } \\
\text { privilegio". } \\
\text { Sucesión monárquica. }\end{array}$ \\
\hline \multirow{3}{*}{$\begin{array}{l}\text { Educación } \\
\text { General } \\
\text { Básica } \\
\text { superior }\end{array}$} & \multirow{3}{*}{$\begin{array}{l}\text { [4] Imperio centralizado y } \\
\text { autocrático: el Sapa inca es } \\
\text { "emperador". } \\
\text { Pirámide jerárquica. } \\
\text { División en cuatro regiones. } \\
\text { Inca hurin como "sumo sacerdote". } \\
\text { Hanan/hurin en las ciudades. } \\
\text { Curacas con cierta autonomía. }\end{array}$} & $\begin{array}{l}\text { [5] Imperio centralizado. } \\
\text { Pirámide jerárquica. } \\
\text { División en } 4 \text { regiones. }\end{array}$ \\
\hline & & $\begin{array}{l}\text { [6] Imperio unificado pero con gobierno } \\
\text { descentralizado. El Sapa Inca es "emperador". } \\
\text { Pirámide jerárquica. } \\
\text { División en cuatro regiones. } \\
\text { Monarquía hereditaria. }\end{array}$ \\
\hline & & $\begin{array}{l}\text { [7] Imperio. } \\
\text { Pirámide jerárquica. } \\
\text { Reciprocidad como sistema de gobierno. } \\
\text { División en cuatro regiones “unidas entre sí". }\end{array}$ \\
\hline \multirow{2}{*}{$\begin{array}{l}\text { Bachillerato } \\
\text { General } \\
\text { Unificado }\end{array}$} & \multirow[t]{2}{*}{$\begin{array}{l}\text { [8] Imperio centralizado, unificado } \\
\text { política y culturalmente. } \\
\text { Pirámide jerárquica. } \\
\text { Monarquía hereditaria. }\end{array}$} & $\begin{array}{l}\text { [9] Imperio } \\
\text { División en cuatro regiones. } \\
\text { Reciprocidad y redistribución. } \\
\text { Monarquía hereditaria. } \\
\end{array}$ \\
\hline & & $\begin{array}{l}\text { [10] Imperio } \\
\text { Pirámide jerárquica. } \\
\text { Monarquía hereditaria "patrilineal". }\end{array}$ \\
\hline
\end{tabular}

Tabla 3. Caracterización política del Tahuantinsuyo en los textos escolares ecuatorianos del período 2016-2019, considerados en el artículo. Fuente: elaboración propia. 


\section{Conclusión: los Andes leídos con categorías europeas}

7. Un caso extremo respecto a la utilización de fuentes totalmente discutibles y superadas es el texto 4, que utiliza en su relato, sin ninguna distancia crítica, la leyenda de los Shyris y del reino de Quito, así como considera que el Inca Atahualpa nació en Quito y no en Cusco. Este tipo de relato, elaborado en el siglo XVIII por el padre jesuita Juan de Velasco, a partir de fuentes desconocidas, tiene un valor literario y ha sido por mucho tiempo uno de los mitos fundantes de la nación ecuatoriana, pero ya desde hace tiempo ha sido desmentido por las investigaciones de corte arqueológico y etnohistórico (Rostworowski, 1988; Salomon, 2011).
Los casos que hemos ido describiendo son un ejemplo de cómo, el uso de determinadas categorías de análisis e interpretación de matriz eurocéntrica pueden llegar a construir una narración muy diferente de los fenómenos sociales y políticos andinos. En el caso que estamos tratando vemos cómo el sistema político incaico puede ser objeto de dos narraciones muy diferentes. La primera narración es la de la historia tradicional, derivada de una lectura superficial y no filtrada de los cronistas españoles que, paralelamente al proceso de conquista, ofrecieron sus descripciones e interpretaciones sobre los pueblos que acababan de someter. Esta narración representa al Tahuantinsuyo como un "imperio" centralizado, regido por una sola figura, el Sapa Inca o Inca Hanan, quien obtenía su cargo de manera hereditaria, y ejercía un poder de tipo autocrático sobre todos sus territorios. La segunda narración, en cambio, ha sido elaborada por la investigación etnohistórica, a través de una crítica, deconstrucción y sucesiva reconstrucción de las fuentes, y ofrece nuevas visiones alternativas sobre lo que pudieron ser las sociedades andinas pre-hispánicas. En ella encontramos elementos diferentes, como la dualidad y el reparto del poder, la reciprocidad como forma de gobierno, la complejidad de los mecanismos sucesorios; se trata de una narración en buena parte aún incompleta y con puntos no siempre claros, con muchos debates internos, pero que va evidentemente en otra dirección respecto a la primera.

En esta contraposición entre narrativas históricas parece claro que los currículos y los libros de texto ecuatorianos se colocan más en el marco de la primera pues, aunque se ha hecho un esfuerzo para introducir nuevos contenidos y muchos autores sean en algunas ocasiones citados (como Murra, Rostworowski, Zuidema y Pease), al final no se ofrece una visión de los fenómenos históricos que se desmarque de la historia tradicional, de su terminología y de sus fuentes. ${ }^{7}$

Esta falta de apropiación de la etnohistoria por los textos escolares ecuatorianos constituye una falta de reconocimiento de la originalidad de la experiencia histórica andina, pues la presenta como los conquistadores españoles quisieron verla: una repetición exótica e iletrada de experiencias históricas vistas en occidente, como el imperio romano o el de Carlos V. No representar elementos como por ejemplo la dualidad y el reparto del poder, es una negación de la singularidad de las experiencias históricas de los pueblos andinos que, paradójicamente, está en parcial contradicción con el currículo cuando pone como objetivo:

\footnotetext{
Valorar los aportes de los pueblos orientales y americanos al acervo cultural humano, por medio del conocimiento de sus más significativos logros intelectuales, científicos, etc., para desechar visiones eurocéntricas y discriminatorias basadas en prejuicios y estereotipos (O.CS.H.5.1) [....así como] Explicar las diversas formas de vida y de organización social de las grandes culturas nativas de América aborigen, en función de valorar su capacidad de innovación y creatividad (CS.H.5.3.2).
}

En nuestra visión, los textos ecuatorianos están fuertemente marcados por un concepto eurocéntrico de "historia", así como por una selección situacional de recuerdos sobre el "pasado" originados por la fuerte tradición historiográfica impuesta por los vencedores de las sociedades latinoamericanas (Gruzinski, 2017), lo que constituye una "usurpación de la memoria" (Galeano, 2010) o un "robo de la historia" (Goody, 2011). En nuestra opinión, el etnocentrismo 
conceptual de los parámetros y categorías occidentales usados en los textos subalternizan a los conceptos andinos de dualismo, pluralidad y equilibrio del poder, negando su función generadora de conocimiento y evidenciando una vez más cómo el llamado "discurso científico" occidental está estrechamente ligado a un proyecto imperial que pasa a través de la dominación epistémica y de la colonialidad del saber (Quijano, 2014). Sea como fuere, y a pesar de las intenciones declaradas en algunos de los documentos examinados -como el Currículo nacional Kichwa, y la Ampliación curricular para el BGU de EIB- las producciones etnohistóricas que abrevan directamente de las epistemes andinas, y que por tanto dan cuenta de manera más fiel del tipo de sociedades que habitaron lo que un día fuera el Tahuantinsuyo, no se incorporan en mayor medida en los textos escolares analizados.

El efecto de este tipo de narración histórica escolar es, entonces, que el estudiantado ecuatoriano no tenga instrumentos para poder conocer alternativas a los modelos históricos de "imperio" y "sociedad centralizada", y entonces tenga más dificultad en llegar a ser consciente de la pluralidad de maneras de imaginar las organizaciones políticas que ha caracterizado a la América prehispánica. A través de las indicaciones curriculares y de los textos, los estudiantes son empujados a concentrarse sobre solo en unas pocas categorías históricas de matriz eurocéntrica, a través de las cuales se reduce y banaliza, para no decir se equivoca, la originalidad de las experiencias andinas. En línea con unas recientes reflexiones de DeCock et al. (2019), consideramos que la representación y enseñanza de una historia tradicional y "unilineal" lleva como última consecuencia a reforzar la lógica del llamado pensamiento TINA (There Is No Alternative), fundado sobre falta de conocimiento y conciencia de las alternativas históricas. En el marco de una enseñanza de la historia que sea funcional a la elaboración de un pensamiento crítico y emancipatorio, es fundamental, en cambio, complejizar para poder tener instrumentos conceptuales que permitan concebir alternativas a las visiones y narraciones ideológicas dominantes.

En conclusión, pensamos que la historia y su enseñanza no deben ser entendidas solo en términos de una averiguación de datos "auténticos", sino más bien como una interpretación a través de la construcción de una narrativa, en el mundo académico y en la educación. Esta narrativa debe ser examinada desde su locus de enunciación (Pratt, 1992), desde sus intenciones y desde las relaciones de poder que se quieren construir (Quijano, 2014). En este sentido, la etnohistoria no debe ser vista como una ciencia más exacta sobre que pasó en América Latina, sino como una narrativa que intenta aproximarse más a la visión de los nativos americanos, ofreciendo no solo datos sino también interpretaciones y sentidos más acordes a la "visión de los vencidos" (Wachtel, 1971). En este sentido, la etnohistoria es una alternativa a una visión tradicional y oficial de la historia, eurocéntrica funcional al dominio colonial, y su adopción en el ámbito educativo tiene el desafío de ofrecer una narrativa verdaderamente emancipadora. 


\section{Fuentes}

\section{Documentación oficial}

» Modelo del Sistema de Educación Intercultural Bilingüe (MOSEIB) (2013). República del Ecuador, Ministerio de Educación.

"Currículo de Educación General Básica (EGB) y Bachillerato General Unificado (BGU) Ciencias Sociales (2016). República del Ecuador, Ministerio de Educación.

»IshkayShimiKawsaypuraKichwaMamallaktayukkunapa Yachayñan - Currículo nacional kichwa intercultural bilingüe de EGB (2017). República del Ecuador, Ministerio de Educación.

»Ampliación Curricular para el Bachillerato General Unificado Intercultural Bilingüe - Lengua y Literatura de las Nacionalidades - Ciencias Sociales - Ciencias Naturales - Educación Cultural y Artística - Educación Física (2017). República del Ecuador, Ministerio de Educación.

\section{Textos escolares}

》S S/A, (2016). Estudios sociales. vol. 5. Quito, Editorial Don Bosco.

» S/A, (2016). Estudios sociales, vol. 9. Quito, Editorial Don Bosco.

» S/A, (2017). Historia, vol. 3. Quito, Editorial Don Bosco.

» Ayala Mora, E. (2017). Estudios sociales, vol. 5. Quito, Corporación Editora Nacional.

» Ayala Mora, E. y G. Ortiz Crespo (2017). Estudios sociales, vol. 8. Quito, Corporación Editora Nacional.

»Castro, B., 2018. Historia, vol. 1. Quito, Edinun.

"Vacas Andrade, D., 2017. Talento en sociales, vol. 5. Quito, Edinun.

»Villa, K. y C. Espín, 2018. Ciencias sociales, vol. 8. Quito, Editorial Educatemas.

»Villacreses, X., 2017. Historia, vol. 1. Quito, Editorial Educatemas.

» Zhingre, R., 2018. Talento en sociales, vol. 8. Quito, Edinun. 


\section{Q Bibliografía de referencia}

»Atienza Cerezo, E. (2006). “Ideología y discurso en los contextos educativos: manifestación del currículo oculto" en Actas del XXXV Simposio Internacional de la Sociedad Española de Lingüística: 135-150. León, Universidad de León.

" Ávila Molero, J. (2000). "Entre archivos y trabajo de campo: la etnohistoria en el Perú", en Degregori, C. I. (coord.), No hay país más diverso. Compendio de antropología peruana: 180-203. Lima, Instituto de Estudios Peruanos.

" Ayala Mora, E. (2015). Historia, tiempo y conocimiento del pasado. Quito, Universidad Andina Simón Bolívar/ Corporación Editora Nacional.

》Benjamin, W. (2008). Tesis sobre la historia y otros fragmentos. México, ITACA/ UACM.

» Bloch, M. (2001). Apología de la historia, o el oficio de historiador. México, Fondo de Cultura Económica.

» Brito Román, J. C. y V. Gámez Ceruelo (2019). La problemática de la formación de la identidad nacional en la enseñanza de la Historia: El caso afroecuatoriano. Revista Electrónica Interuniversitaria de Formación del Profesorado 22 (2): 123-136.

" Burgos, H. (1995). El Guamán, el Puma y el Amaru. Formación estructural del gobierno indígena en el Ecuador. Quito, Abya-Yala.

" Campos Pérez, L. (2010). La imagen del indio en la construcción histórico-cultural de la identidad. Estudio comparado de su representación iconográfica en los manuales escolares de México y España (1940-1945). Memoria y Sociedad 14 (28): 107-124.

"Carretero, M. (2007). Documentos de identidad. La construcción de la memoria histórica en un mundo global. Buenos Aires, Paidós.

»Cerón Rengifo, C. P. (2015). Amerindios y europeos en manuales escolares de historia de América, Colombia (1975-1990). Anuario Colombiano de Historia Social y de la Cultura 42 (1): 83-113.

»Chaupis Torres, J. (2015). Los textos escolares en conflicto con la subalternidad: la guerra del Pacífico en las aulas. Diálogo Andino 48: 99-108.

» Chervel, A. (1988). L'Histoire des disciplines scolaires. Réflexions sur un domaine de recherche. Histoire de léducation 38: 59-119.

" Chevallard, Y. (1985). La transposition didactique: du savoir savant au savoir enseignée. Grenoble, La Pensée Sauvage

"Choppin, A. (2008). Le manuel scolaire, une fausse évidence historique. Histoire de l'éducation 117: 7-56.

» Cibotti, E. (2016). América Latina en la clase de historia. México, Fondo de Cultura Económica.

" Conrad, S. (2017). Historia global. Una nueva visión para el mundo actual. Barcelona, Planeta.

"Crestani, L. (2003). Sem vez e sem voz. O negro nos textos escolares. Passo Fundo, Universidade de Passo Fundo Editora.

》De Certeau, M. (1975). L'écriture de l'histoire. Paris, Gallimard.

" De Cock, L. (2018). Sur l'enseignement de l'histoire. Débats, programmes et pratiques du XIXe siècle aujourd'hui. Paris, Libertalia. 
» De Cock, L., Larrère, M. y G. Mazeau (2019). L'Histoire comme émancipation. Marseille, Agone.

» Del Pozo, M. (2008). Educación y construcción de las identidades nacionales. Historia de la Educación 27: 27-37.

»Duviols, P. (1980). Algunas reflexiones acerca de la tesis de la estructura dual del poder incaico. Histórica 4 (2): 183-196.

» Ferro, M. (1981). Comment on raconte l'Histoire aux enfants à travers le monde entier. Paris, Payot.

» Florescano, E. (2000). Para qué estudiar y enseñar la historia. México, Instituto de Estudios Educativos y Sindicales de América.

»Florescano, E. (2012). La función social de la historia. México, Fondo de Cultura Económica.

» Geertz, C. (1973). The Interpretation of Cultures. New York, Basic Books.

» Goody, J. (2011). El robo de la historia. Madrid, Akal.

» Granda Merchán, S. (2003). Textos escolares e interculturalidad en Ecuador. Quito, Abya Yala/ CEN-UASB.

» Gruzinski, S. (2013). L'histoire, pour quoi faire? Paris, Fayard.

» Gruzinski, S. (2017). La machine à remonter le temps. Quand l'Europe s'est mise à écrire l'histoire du monde. Paris, Fayard.

» Hernández Astete, F. (2002). “El poder incaico: una aproximación a la figura del Inca hurin” en Flores Espinoza, J. y R. Varón Gabai (eds.), El hombre y los Andes. Homenaje a Franklin Pease G.Y. Tomo II: 75-83. Lima, Institut Français d'Études Andines.

» Hernández Astete, F. (2012). La sucesión entre los incas. Chungara. Revista de antropología chilena 44 (4): 655-667.

» Julia, D. (1995). La culture scolaire comme objet historique. The colonial experience in education. Paedagogica Historica (Series I): 353-382.

» Marimán, P. yJ. Flórez (1996). La sociedad mapuche en la enseñanza de la historia en Chile. Temuco-Chile, Universidad de la Frontera.

» Morgado Fernández, P. y S. Fernández-Silva (2018). La Selección terminológica referida al golpe y dictadura militares en textos escolares de historia durante el periodo 20022014. Logos. Revista de Lingüística, Filosofía y Literatura 28 (1): 151-169.

» Murra, J. V. (1975). Formaciones políticas y económicas del mundo andino. Lima, Instituto de Estudios Peruanos.

» Oberem, U.(1985). “La sociedad indígena durante el periodo colonial de Hispanoamérica” en Miscelánea Antropológica Ecuatoriana (5): 161-218. Guayaquil, Publicación de los Museos del Banco Central del Ecuador.

»Pärssinen, M. (2003). Tawantinsuyu. El estado inca y su organización política. Lima, Institut Français d'Études Andines.

»Pease G. Y., F. (1995). Las crónicas y los Andes. México, Fondo de Cultura Económica.

» Pratt, M. (1992). Ojos imperiales. Literatura de viaje y transculturación. México, Fondo de Cultura Económica.

»Quijano, A. (2014). “Colonialidad del poder y clasificación social” en De Sousa Santos, B. y M. P. Meneses (eds.), Epistemologías del Sur (Perspectivas): 67-143. Madrid, Akal.

» Ramón, G. (1991). “Los indios en la construcción del Estado nacional” en Bonilla, H. (comp.), Los Andes en la encrucijada. Indios, comunidades y Estado en el siglo XIX: 419-457. 
Quito, Ediciones Libri Mundi-Enrique Grosse Luemern/ FLACSO.

» Regalado de Hurtado, L. (1993). Sucesión incaica. Aproximación al mando y poder entre los Incas a partir de la crónica de Betanzos. Lima, Pontificia Universidad Católica del Perú.

» Rockwell, E. (1986). Cómo observar la reproducción. Revista Colombiana de Educación 17 (1).

» Rockwell, E. (1995). “En torno al texto: tradiciones docentes y prácticas cotidianas” en Rockwell, E. (ed.), La escuela cotidiana: 198-222. México, Fondo de Cultura Económica.

» Rodríguez Cruz, M. (2018). Construir la interculturalidad. Políticas educativas, diversidad cultural y desigualdad en Ecuador. Íconos. Revista de Ciencias Sociales 60: 217-236.

» Rodríguez Ledesma, X. (2012). “Tiempos fronterizos, diversidad en la historia”, en Plá, S., Rodriguez Ledesma, X y V. Gómez Gerardo (eds.), Miradas diversas a la enseñanza de la historia: 69-89. México, Universidad Pedagógica Nacional.

» Rostworowski, M. (1983). Estructuras andinas del poder. Ideología religiosa y política. Lima, Instituto de Estudios Peruanos.

» Rostworowski, M. (1988). Historia del Tahuantinsuyu. Lima, Instituto de Estudios Peruanos.

»Salomon, F. (2011). Los señores étnicos de Quito en la época de los incas. La economía política de los señoríos norandinos. Quito, Instituto Metropolitano de Patrimonio.

»Soler Castillo, S. (2008). Pensar la relación análisis crítico del discurso y educación. El caso de la representación de indígenas y afrodescendientes en los manuales escolares de ciencias sociales en Colombia. Discurso \& Sociedad 2 (3): 642-678.

»Spivak, G. C. (2010). Crítica de la razón poscolonial: hacia una crítica del presente evanescente. Madrid, Ediciones Akal.

» Todorov, T. (1987). La conquista de América. El problema del otro. Buenos Aires, Siglo XXI.

"Valls Montés, R. (2001). Los estudios sobre los manuales escolares de historia y sus nuevas perspectivas. Didáctica de las Ciencias Experimentales y Sociales 15: 23-36.

»Wachtel, N. (1971). La vision des vaincus. Les Indiens du Pérou devant la conquête espagnole. 1530-1570. Paris, Gallimard.

»Wachtel, N. (1973). Sociedad e ideología. Ensayos de historia y antropología andinas. Lima, Instituto de Estudios Peruanos.

»Wachtel, N. (2001). El regreso de los antepasados. Los indios urus de Bolivia, del siglo XX al XVI. México, Fondo de Cultura Económica.

"Walsh, K. (2013). Pedagogías decoloniales. Prácticas insurgentes de resistir, (re)existir y (re) vivir. Quito, Abya Yala. (Tomo I).

»Zuidema, R. T. (1964). The Ceque System of Cusco. The Social Organization of the Capital of the Inca. Leiden, Brill.

»Zuidema, R. T. (1989). Reyes y guerreros. Ensayos de cultura andina. Lima, Fomciencias. 